\title{
As normas de radioproteção e o uso dos equipamentos de proteção individual na concepção dos cirurgiões-dentistas
}

\author{
Radioprotection norms and the use of individual protection \\ equipments from the view of surgeon-dentists
}

Ricardo Andrade Santos ${ }^{1}$

Antônio Carlos de M iranda ${ }^{1}$

Edna da Costa Silva ${ }^{1}$

1 Instituto de Pesquisas

Clínicas Evandro Chagas, Fundação Oswaldo Cruz. Av. Brasil 4365, $M$ anguinhos. 21040-900 Rio deJaneiro RJ. ricardo.andrade@ipec.fiocruz.br
Abstract Although the odontology professional recognizes the existence of norms most of them had not demonstrated to perceive the fair and precise need of clarification. The perception lack displays to some problems as: lack of information on the necessity of accomplishment of periodic medical examinations of the professionals, lack of knowledge in the correct use of the equipment of rays- $x$, unfamiliarity of the necessity of periodic calibration of the device of rays- $x$, the inefficiency in thefulfilment of theradiation protection norms, the inadequate use of the equipment of individual protection (EPI) and absence of a manual of norms of the professional activities. Based in these results it can be concluded that the surgeon-dentists do not withhold the necessary knowledge on the norms of radiation protection and the correct use of the equipment of individual protection. Thus theimplementation of a continued education program based on the reality of the dentist professional will beableto solvechronic problemsidentified in this study in the fulfilment of the requirements of the similar norms of radiation protection, and providing safe manuscript of the equipment of rays- $x$ in the dentistry offices.

Key words X-rays, Surgeon-dentists, Equipment of individual protection, Norms, Radiation protection
Resumo M esmo reconhecendo a existência das normas, a maior parte dos profissionais de odontologia não demonstra perceber a necessidade justa e precisa de esclarecimento. A falta de percepção expõea vários problemas como falta de informação sobre a necessidade de realização de exames médicos periódicos dos profissionais, falta de conhecimento na correta utilização do equipamento de raios $X$, desconhecimento da necessidade de calibração periódica do aparelho de raios $X$, ineficiência no cumprimento das normas de radioproteção, uso inadequado do equipamento de proteção individual (EPI) e ausência de um manual de normas das atividades profissionais. Com bases nesses resultados, pode-se chegar à conclusão de que os cirurgiões-dentistas não detêm 0 conhecimento necessário sobre as normas de radioproteção eda correta utilização do EPI . Assim, acredita-se que implementação do programa de educação continuada a partir da realidade do profissional de odontologia forneça os mei os para resolução de problemas crônicos detectados nesteestudo no cumprimento das exigências das normas de radioproteção e afins, proporcionando manuseio seguro do equipamento de raios $X$ no consultório odontológico.

Palavras-chave Raios X, Cirurgiões-dentistas, Equipamento de proteção individual, N ormas, Radioproteção 
A história do desenvolvimento da energia nuclear foi acompanhada por acontecimentos como as explosões em Hiroshima e Nagasaki. Esses fatos ocorreram quando não se tinha ainda 0 entendimento adequado sobre os efeitos biológicos das radiações ionizantes. Diversos radiologistas morreram ao redor de 1922 em consequência dos danos causados pelas radiações. Tais fatos despertaram a atenção da comunidade científica e fizeram com que fosse criado um novo ramo da ciência: a proteção radiológica, com a finalidade de proteger os indivíduos, regulamentando e limitando o uso das radiações em condições aceitáveis.

A partir do século XIX, as fontes naturais de radiação somaram-se às produzidas pelo homem, tais como os raios $X$, as inúmeras radiações médicas e industriais de radioisótopos e os contaminantes ambientais gerados pelas explosões nucleares. Assim, os seres humanos estão permanentemente expostos a uma radiação de fundo, que é a soma da radiação natural com a $\operatorname{artificial}^{1-8}$.

As aplicações médicas de radioisótopos e raios $X$ são responsáveis pela quase totalidade da dose de radiação artificial à qual o homem está exposto. $\mathrm{Na}$ radioterapia, as doses utilizadas são muitas el evadas, mas como o número de pessoas submetidas a essa prática médica é relativamente reduzido, sua contribuição para a dose global re cebida pela população não é muito grande ${ }^{9}$.

Segundo a Comissão Nacional de Energia Nuclear (CNEN) $)^{1-8}$, no início da era nuclear houve um incentivo muito grande para o desenvolvimento de aplicações dos materiais radioativos. 0 objetivo era encontrar usos benéficos queproporcionassem retorno econômico, conhecimento cientifico avançado e, principalmente, melhorasse a qualidade de vida da sociedade. Nos dias de atuais, a energia nuclear é utilizada para geração de energia elétrica, sendo uma forte concorrente com os demais recursos energéticos. Os materiais radioativos por ela produzida são largamente utilizados na medicina, na indústria e na agricultura.

0 crescente uso da radiologia médica e odontológica faz com que sua utilização seja profundamente estudada devido à necessidade de se reduzirem as radiações recebidas pelos pacientes $e$ profissionais (técnicos de raios $X$, médicos radiologistas, cirurgiões-dentistas eauxiliares), uma vez que estes recebem uma quantidade significativa de radiação fornecida em exames radiográficos.

Devido a sua grande utilidade e ben efício no diagnóstico de patologias eafins, a utilização dos raios $X$ é uma necessidade, assim como o desenvolvimento demecanismos de proteção, para que o seu uso seja o mais proveitoso e menos nocivo possível. Considerando o estado do desenvolvimento tecnológico atual eas experiências adquiridas ao longo dos anos, utilizam-se normas e regulamentos específicos para radiologia ${ }^{10}$, os quais, uma vez seguidos na prática, garantem a padronização dos requisitos mínimos de radioproteção, reduzindo as doses de radiação a níveis aceitáveis e proporcionando segurança aos usuários. Por sua vez, a existência denormas e legislações pertinentes por si só não garante a qualidade na utilização dos raios $X$ em consultórios odontológicos e ambientes hospitalares.

Já édeconhecimento público queos riscos da utilização inadequada da radiação podem ocasionar uma modificação (mutação) do código genético (DNA - ácido desoxirribonucleico) das células que constituem os órgãos da espécie humana; uma vez modificado o DNA da célula, pode ser decretada a morte celular ea incapacidade de reproduzir-se. Assim, autoridades e estudiosos (Mouriquand, Pater, Darnault, Gilly, Jalbert e Wolff) do assunto sentiram a necessidade de regulamentar a sua utilização, sendo que no Brasil a maior parte dos estados carece de pessoal especializado e de normas de segurança adequadas para as atividades afins ${ }^{10}$.

Com base nessas situações, os maiores prejudicados são os profissionais de radiologia e a população consumidora desses serviços, pois devido à inadequação de técnicas, acessórios, material de consumo e equipamentos de proteção individual, todos ficam expostos ou se submetem a altas doses de radiação ionizante ao executarem as técnicas referidas - o quevem prejudicar a saúde e acarretar, consequentemente, uma diminuição da qualidade de vida desses profissionais.

É inegável e evidenteque o avanço da tecnologia aprimorou o diagnóstico em odontologia. Contudo, evolução tecnológica, conhecimento sobrea manutenção e periculosidade dos equipamentos não progridem na mesma proporção, provocando um descompasso entre os benefícios que a modernização traz para a saúde dos pacientes e os possíveis problemas que envolvem a questão. 


\section{Colaboradores}

RA Santos participou da elaboração do artigo, de sua discussão e redação e da revisão do texto. EC Silva participou da revisão do texto e $A C$ Miranda participou das discussões para a elaboração do manuscrito.

\section{Referências}

1. Comissão Nacional de Energia Nuclear (CNEN). N ormas - Diretrizes básicas de radioproteção NE 3.01. 2005; [acessado 2007 mar 15]. Disponível em: http:/ /www.cnen.gov.br/seguranca/normas/normas.asp

2. Comissão Nacional de Energia Nuclear (CNEN). N ormas - Serviço de radioproteção NE 3.02 - 1988; [acessado 2007 mar 16]. Disponível em: http://www.cnen. gov.br/seguranca/normas/normas.asp

3. Comissão Nacional de Energia Nuclear (CNEN). Normas - Certificação da qualificação de supervisores de radioproteção NE 3.03 - 1999; [acessado 2007 mar 16]. Disponível em: http://www.cnen.gov.br/ seguranca/normas/normas.asp

4. Comissão Nacional de Energia Nuclear (CNEN). N ormas - Requisitos de radioproteção e segurança para serviços de medicina nuclear NE 3.05 - 1996; [acessado 2007 mar 20]. Disponível em: http://www. cnen.gov.br/seguranca/normas/normas.asp

5. Comissão N acional de Energia Nuclear (CNEN). Normas - Requisitos de radioproteção e segurança para serviços de radioterapia NE 3.06 - 1990; [acessado 2007 mar 20]. Disponível em: http://www.cnen. gov.br/seguranca/normas/normas.asp

6. Comissão N acional de Energia Nuclear (CNEN). N ormas - Requisitos para o registro de pessoas físicas para o preparo, uso e manuseio de fontes radioativas NE 6.01 - 1998; [acessado 2007 mar 20]. Disponível em: http://www.cnen.gov.br/seguranca/normas/ normas.asp

7. Comissão Nacional de Energia Nuclear (CNEN). Normas - Licenciamento das instalações radiativas NE 6.02 - 1998; [acessado 2007 mar 22]. Disponível em: http://www.cnen.gov.br/seguranca/normas/normas. asp

8. Comissão N acional de Energia Nuclear (CNEN). Normas - Gerência de Rejeitos Radioativos em Instalações Radiativas NE 6.05 - 1985; [acessado 2007 mar 20]. Disponível em: http://www.cnen.gov.br/seguranca/normas/normas.asp

9. Schuch LA. Introdução ao estudo dos raios cósmicos e sua interação com a atmosfera terrestre. IN PE5243-RPQ/649; 1991.

10. Cardoso EM, Nouailhetas Y. Apostilas educativas: Radioatividade, Energia Nuclear, Aplicações da Energia Nuclear e M ódulo de Informação Técnica. Comissão nacional de Energia Nuclear (CNEN). [site na Internet] 2007. [acessado 2007 mar 20]. Disponível em http://www.cnen.gov.br/ensino/ apostilas.asp

Artigo apresentado em 31/07/2007

A provado em 10/10/2007

Versão final apresentada em 04/12/2007 